\title{
Transition towards an energy-efficient scientific Office Setup in Austria's largest (Plus-)Plus-Energy Office Building - an Analysis
}

\author{
Alexander David ${ }^{1, *}$ and Thomas Bednar ${ }^{1}$ \\ ${ }^{1}$ TU Wien, Institute of Material Technology, Building Physics and Building Ecology, Karlsplatz 13/207-02, A-1040 Vienna, Austria
}

\begin{abstract}
Near the center of Vienna one can find the world's first office tower which was designed to feed more energy into the power grid than is required to operate and use the building. This building is the result of the refurbishment of an over 40 years old high-rise building. The so called "(Plus-)Plus-Energy Office High-Rise Building" offers office space for several institutes of the TU Wien. The building was planned and simulated under the premise that every office occupant uses highly energy-efficient IT-hardware which would result in an average electrical power consumption of approximately 50 Watts per office workplace. Moreover, the cooling system of the building was planned for this case, allowing only for a minimal internal thermal load. To realize the simulation results, conventional office IT-hardware needs to be substituted by energy-efficient one and all intensive computing processes, e.g. simulations, ought to be outsourced into the building's server room. This research presents the challenges faced during the transition from a conventional scientific office setup to an energy-efficient one. The method which was used to encourage the occupants to participate in this transition process will be discussed and the impact on the building's energy consumption will be shown.
\end{abstract}

\section{Introduction}

In Vienna at TU Wien's Campus "Getreidemarkt" one can find an eleven-story high-rise building complex, which is the result of the refurbishment of an over 40 years old high-rise laboratory building and now offers space for lecture halls, a library, an event hall, some research facilities, but mostly office floors [1].

The office floors of the building complex and their share of the server room and utility management areas is referred to as "(Plus-)Plus-Energy Office High-Rise Building". In the following parts of this work the term "building" refers only to the "(Plus-)Plus-Energy Office High-Rise Building".

The focus of the building's refurbishment was an extreme reduction of its energy consumption to a level where it is possible to cover it with energy supply from local renewable resources on an annual basis [2]. Usually this type of buildings is referred to as "Net Zero Energy Building" or "Plus-Energy Building". As the aim of the building concept is that the supply from local renewable resources covers both the energy needed to operate and use the building, the term "Plus-Plus-Energy Building" would be a better fit. The first "Plus-" is put in brackets in order to indicate that the building concept could theoretically achieve the set aim but due to several reasons, which were mostly already discussed in [2], the planned energy saving potential could not be fully realized.
Other office tower projects with comparable ambitions regarding the energy consumption and supply from local renewable resources, e.g. the Elithis Tower in France [3] or the Powerhouse Kjørbo and Powerhouse Brattøra in Norway [4] do not include the energy consumption for the usage (appliances/plug-loads) in their boundaries. It is therefore assumed that in all three cases there were no special processes in place, which help implementing the usage concept that the buildings were designed for.

Due to its significant impact on the overall energy consumption, the usage concept is one of the most important parts of the design concept of the (Plus-)PlusEnergy Office High-Rise Building. Accordingly, it was necessary to set up a process for the implementation of the usage concept together with the building's tenants. This paper describes this process itself and discusses its impact on the building's energy consumption.

One of the main aspects of the building's design concept is that no energy-intensive appliances are located in the office spaces. The offices shall only be equipped with very energy-efficient office equipment. All other very energy-demanding services needed for scientific purposes ought to be relocated from the offices into the "research"-part of the server room and are thus excluded from the building's boundaries. Only the "office" part of the server room, hosting webservers, file servers and database servers, is included in the boundaries $[2,5-7]$.

* Corresponding author: alexander.david@tuwien.ac.at 
The exclusion of the "research"-part of the server room from the building's boundaries is necessary because TU Wien is not the typical office user, like e.g. an insurance.

Fig. 1 illustrates the usage concept of the (Plus-)PlusEnergy Office High-Rise Building and compares it with the conventional usage concept of the institutes which occupy the building.

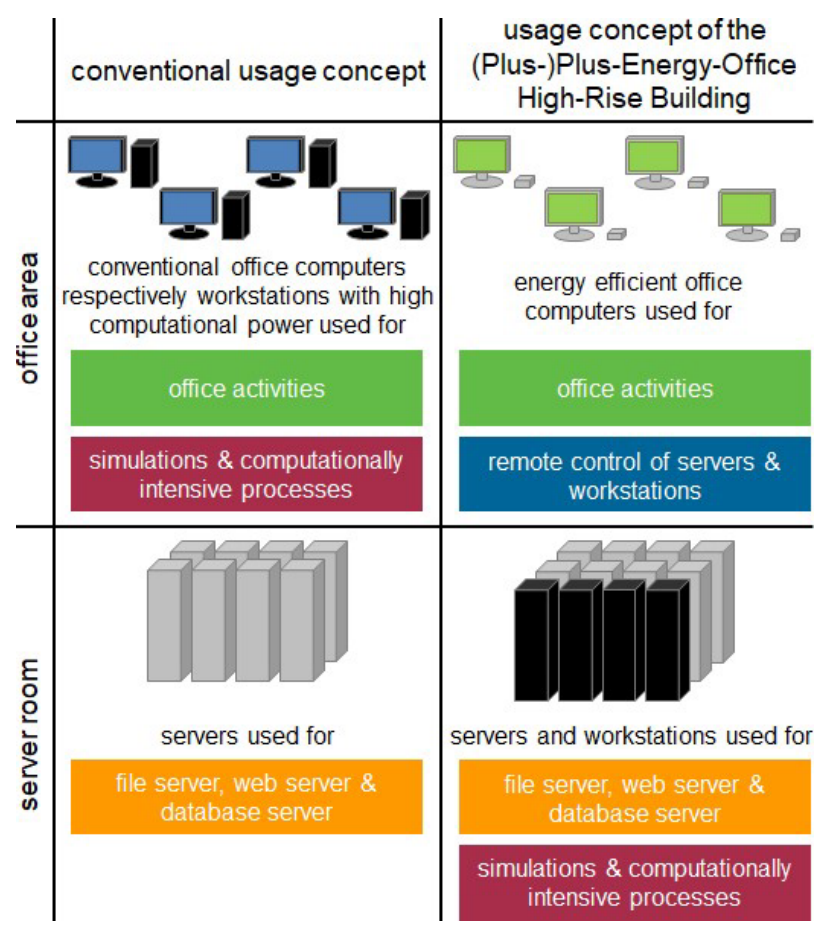

Fig. 1. Comparison of the (Plus-)Plus-Energy Office High-Rise Building's usage concept and the conventional usage concept.

The illustration of the conventional usage concept shows how the offices of many of TU Wien's institutes are usually set up: Workstations are usually located directly in the office area, they are mainly used for simulations and computationally intensive processes and partially also for office activities. The rest of the office activities is conducted on conventional office computers and laptops. Such a scientific office setup, incl. telephone and computer monitors, amounts to an average consumption of electrical power of approximately 250 Watts per office workplace during office hours. The heat generated due to this power output poses a challenge for energy-efficient cooling systems like underfloor cooling and would sometimes result in too high room temperatures.

In the case of the usage concept of the (Plus-)PlusEnergy Office High-Rise Building, the energydemanding services used for scientific purposes, namely simulations and computationally intensive processes, are simply relocated to the server room. There they can be accessed via a remote connection over the building's ethernet network. As this remote control and the remaining typical office activities can easily be conducted on less energy-consuming computers, energy consumption within the office area is reduced. With this usage concept, the average consumption of electrical power for one office workplace decreases to 50 Watts during office hours. This is low enough to be cooled away by the building's underfloor cooling and night ventilation system $[1,7]$.

Another reason for concentrating the energydemanding processes in the server room is that with this setup it is easier to recover the waste heat of these processes and reuse it for other purposes. In case of the (Plus-)Plus-Energy Office High-Rise Building, the waste heat is supposed be used as source for heating energy during the winter months $[1,7]$. As already indicated by the monitoring results in [2], this energy recovery potential could not be fully utilized.

Fig. 2 depicts the building's timeline during and after the time of the refurbishment and the timespan analyzed in this work.

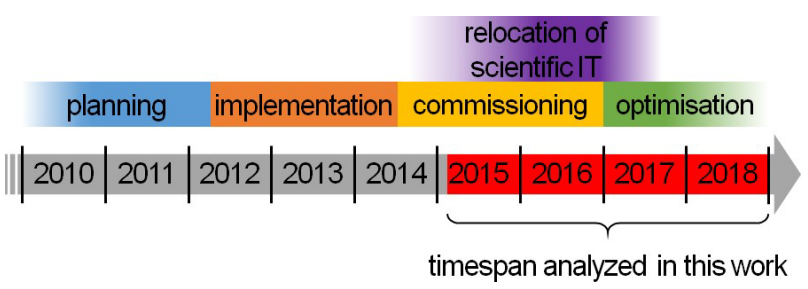

Fig. 2. Depiction of the refurbishment's timeline and processes.

At the end of summer 2014 the new occupants of the building, institutes of TU Wien's Faculty of Mechanical and Industrial Engineering, started to resettle into the building. They brought their old IT equipment and set it up in the building's offices, as described in the conventional usage concept in Fig. 1. The process "relocation of scientific IT" depicted in Fig. 2 indicates how long it took to switch from the conventional usage concept to the usage concept the building originally was designed for.

As the resettlement itself was a time-consuming process, which disturbed the usual workflow of the institutes, the relocation of scientific IT was not conducted during the resettlement. Initially it was expected that the process would be completed by the end of 2015, but due to several challenges the completion took until summer 2017:

- The initially offered IT solution for the relocation of highly energy-demanding services did not fully fit the needs of all workgroups of the institutes. It was necessary to develop individual solutions for each workgroup.

- The old workstations of the institutes were already set up as needed for the scientific work. To set up new systems in the same way needed time and coordination with the time schedule of the employees and their projects.

- Many workstations were used by PhD students, whose employment contracts were scheduled to end within months after the resettlement. It was waited for the end of their contracts to retire the inefficient hardware rather than initiate the relocation of processes from their workstations to the server room. In some cases, the PhD 
student's contracts were extended for some months and so was the usage of their old workstations.

Even though the relocation process is officially completed, there are still some remaining workstations used in the building's office area. As the building's monitoring- and optimization project ended at the end of 2017, there are no actual numbers for the following years. At the end of 2017 there were on average three workstations left on each floor, some of them were used very seldom. The number of remaining workstations is negligible, so that the building's cooling systems are not impaired in their operation.

\section{Method}

Several departments and institutes of TU Wien, as well as external companies were involved in the process of developing suitable IT solutions for the building's institutes:

- TU Wien's Information Technology Solutions department

- TU Wien's Real Estate and Facility Management department

- Several institutes of the TU Wien Faculty of Mechanical and Industrial Engineering, which are the building's occupants

- TU Wien's dean's offices, which are also building's occupants but do not operate workstations

- TU Wien's members of the Research Division for Building Physics, which were involved in the building's monitoring- and optimization project

- Workgroup of Architects Hiesmayr-GallisterKratochwil (the building's general planner)

- Schöberl \& Pöll GmbH (building physics and energyefficiency consultants)

The goal was that only highly energy-efficient office computers are used in the office area so that the average consumption of electrical power does not exceed 50 Watts per workplace. To reach this limit it was necessary to develop a concept which deals with the building's occupants old computer screens, office computers and workstations whose operation would exceed the limit. It was assumed that the laptops used in the building were appropriate for reaching this limit and if not, that they are mobile consumers which are not always present and therefore negligible.

In order to determine whether a standard computer screen or office computer is not energy-efficient enough to achieve the 50 Watts goal, it needed to be measured. This was done by a simple power meter which was temporarily plugged between the socket and the computer screen's or office computer's power cable.

The solution for the computer screens was quite simple: Exchange old computer screens for new, more energy-efficient and most of the time even larger computer screens.

As for the office computers, the solution was also quite simple: Exchange old office computers for extremely energy-efficient mini PCs, with a form factor, which is marketed by Intel as "Next Unit of Computing" (NUC). Their small size freed a significant amount of office space. Only a few office computers were exchanged for new energy-efficient desktop systems.

For the workstations there was not only one solution but four. They will be discussed in more detail in subchapter 2.1.

\subsection{IT solutions for the relocation of energy- demanding services into the server room}

The old workstations were mainly used for heavy-duty computing, e.g. simulations or calculations, so these machines usually had powerful CPUs. Some of the applications needed not only a powerful CPU but also a powerful GPU, thus many of the workstations were equipped with dedicated graphic cards.

\subsubsection{Resettlement of existing workstations}

Directly resettling the existing desktop workstations seems to be the easiest solution, but due to limited space in the server room, this solution could only be used for few workstations.

\subsubsection{Rack workstations}

The first solution which was developed especially for the users with a need for workstations with dedicated graphic cards were the so called "rack workstations". A rack workstation is in principle a usual workstation with a dedicated graphics card built into a 19" frame which has only one height unit. With this format more workstations can fit into one server rack than when filling it with desktop workstations.

In order to achieve a fast remote connection with high picture quality, the software "HP Remote Graphics Software" was acquired. It enables the clients in the office, namely the energy-efficient mini PCs, energyefficient desktop computers or laptops, to control the rack workstations remotely.

Most of the rack workstations had a standard configuration of $4 \mathrm{CPU}$ cores, $32 \mathrm{~GB}$ RAM and a dedicated graphics card with 2048 MB RAM. Some of the rack workstations were equipped with different components so that they fit better to the need of their users. There were even configurations without a dedicated graphics card.

The main disadvantage of the rack workstations is that usually only one user can access them at a time.

\subsubsection{Linux multi-user workstation}

Some of the workgroups work with Linux tools that can be accessed via a terminal. These groups decided for servers with 24/32 CPU cores, 384/512 GB RAM and no dedicated graphics cards.

The servers only have a height of two height units but can supply several users simultaneously. Compared to the resettlement of existing workstations and the rack workstations, this is a solution, which needs comparably little space per user in the server rack. 


\subsubsection{Server for virtual machines}

One workgroup decided for two identical servers which are optimized as servers for virtual machines. The main advantage of this solution is that each virtual machine can be set up with whatever operation system needed and can be tailored to fit the specific needs of each user.

Both servers are equipped with $40 \mathrm{CPU}$ cores, 256 GB RAM and a 4 GPU graphics card with 16 GB RAM that allows virtualization of the GPU. The virtual machines are then set up and managed via the software "VMware hypervisor".

Each of these servers also has a height of two height units and therefore offers a similar space per user ratio as the Linux multi-user workstations.

\subsection{Process for the exchanging of old IT equipment}

Funding for the new IT hardware was supplied by TU Wien's Real Estate and Facility Management department. As this department handles both, complaints about indoor climate and energy bills, it has a definite interest that the building achieves a comfortable indoor climate with minimal energy consumption.

There was a simple process for the old computer screens and old office computers: If the screen or computer is not energy-efficient enough to achieve a 50 Watts workplace, they could simply be exchanged for new ones. Occupants could exchange old computer screens for energy-efficient $24 " / 27$ " computer screens and old computers could be exchanged for mini PCs with i5 processor without a dedicated graphics card or preconfigured energy-efficient desktop systems with a dedicated graphics card. The old computer screens and office computers were then donated to a charitable organization, which refurbishes old hardware.

As the old workstations were still valuable and some of them were quite new, they did not have to be exchanged for one of the IT solutions described in subchapter 2.1. Instead they should have been taken offline and reused at other offices or facilities of TU Wien, e.g. at a laboratory or a test rig. Alternatively, they could be sold by the institutes themselves.

Due to the fact that every institute was equipped with a different number of workstations of different configurations and age, it was necessary to implement a credit system to evaluate the computational and energetical worth of each workstation, which was taken offline in the building.

\subsubsection{Credit system for workstations}

The credit system is a practical approach from a building engineer's point of view. The purpose of this system was to calculate for each institute how expensive their remote IT solutions could be.

In order to define a reference point, which can then be utilized to estimate the worth of the old workstations, the retail costs of the main components of the standard rack workstation were used. As the sum of the retail costs of the main components was a little bit higher than the price of the full rack workstation with standard configuration, there was no further scaling. These costs were then set in relation to the main performance parameters of each component and thus the following three factors could be calculated as formulated in (1), (2) and (3).

With $C_{\mathrm{P}, \mathrm{RWS}}$ as the processor's costs in $€, N_{\mathrm{RWS}}$ as the processor's number of physical cores and $F_{\mathrm{RWS}}$ as the processor's base frequency in $\mathrm{Hz}$, the cost factor for processors $f_{\mathrm{P}}$ in $€ / \mathrm{Hz}$ is calculated as:

$$
f_{\mathrm{P}}=C_{\mathrm{P}, \mathrm{RWS}} /\left(N_{\mathrm{RWS}} \cdot F_{\mathrm{RWS}}\right)
$$

With $C_{\mathrm{R}, \mathrm{RWS}}$ as the RAM's costs in $€$ and $R_{\mathrm{RWs}}$ as the RAM's memory capacity in GB, the cost factor for RAM $f_{\mathrm{R}}$ in $€ / \mathrm{GB}$ is calculated as:

$$
f_{\mathrm{R}}=C_{\mathrm{R}, \mathrm{RWS}} / R_{\mathrm{RWS}}
$$

With $C_{\mathrm{G}, \mathrm{RWS}}$ as the dedicated graphics card's costs in $€$ and $G_{\mathrm{RWS}}$ as the dedicated graphics card's memory capacity in MB, the cost factor for dedicated graphics cards $f_{\mathrm{G}}$ in $€ / \mathrm{MB}$ is calculated as:

$$
f_{\mathrm{G}}=C_{\mathrm{G}, \mathrm{RWS}} / G_{\mathrm{RWS}}
$$

After calculating these factors, for each old workstation, its value $V$ in $€$ was then calculated by evaluating the following parameters and applying them to (4):

- $N$, the workstation's processor's number of physical cores

$-F$, the workstation's processor's base frequency in $\mathrm{Hz}$

- $R$, the workstation's RAM's memory capacity in GB

- $G$, the workstation's dedicated graphic card's memory capacity in MB (Note: if there was no dedicated graphic card, $G$ was zero)

$$
V=f_{\mathrm{P}} \cdot(N \cdot F)+f_{\mathrm{R}} \cdot R+f_{\mathrm{G}} \cdot G
$$

The $V$ values for each workstation which should be taken offline in the (Plus-)Plus-Energy Office High-Rise Building were calculated. The sum of each workgroup's workstations' $V$ values then equaled the budget that the workgroup could use to order the hard- or software solutions presented in subchapter 2.1.

The parties involved in the process of relocating scientific IT into the server room are well aware that the credit system has several flaws, e.g. that institutes which already had a lot of workstations benefited the most from this system. Nevertheless, the system was well accepted.

\subsection{Energy reduction potential}

Fig. 3 shows three cases of relocating scientific IT and exchanging old IT equipment and their respective estimated impacts on the building's energy consumption.

If case 1 is realized, the consumption of electrical energy is not only shifted from the office area to the server room, but there is also an overall consumption reduction. As the rack workstations are approximately as efficient as the old workstations, this can be attributed 
mainly to the exchange of old computer screens and desktop computers.

The other two cases show that there is also the danger of an increased energy consumption.

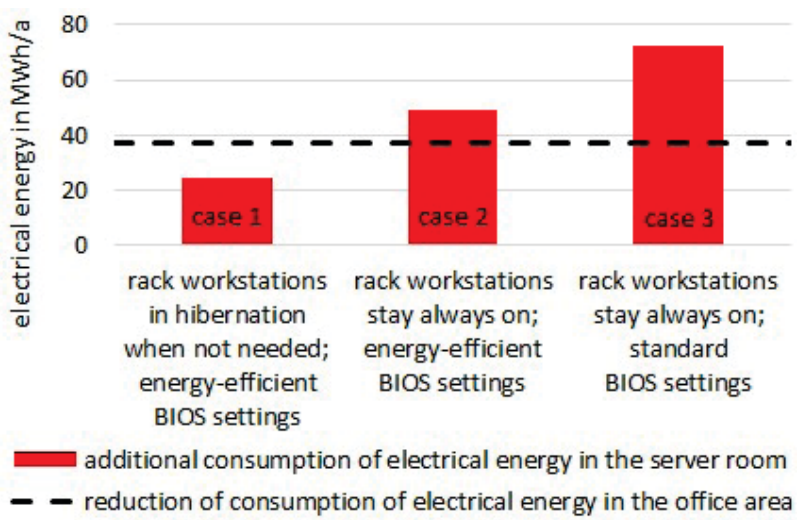

Fig. 3. Depiction of three cases of the expected impact of the relocation of scientific IT and the accompanying exchanging of old IT equipment as described in 2.2.

By comparing case 1 and 2, one can see how much additional electrical energy is consumed when the rack workstations stay always on and are never suspended to hibernation mode when not needed.

Case 3 shows that if neither the rack workstations are suspended nor their BIOS settings adjusted to an energyefficient mode, there is twice as much additional consumption in the server room than consumption reduced in the office area.

\subsection{Energy monitoring}

In order to evaluate whether the building's real energy consumption and energy supply correspond to the respective design values, an extensive energy monitoring system was installed in the building.

On each floor there is at least one electricity meter measuring total electricity consumption on this floor. On two of the eight office floors there are additional submeters for the detailed measurement of different groups of electrical consumers, e.g. computers or lighting. The measurements of those two floors form the basis for the extrapolation of the electricity consumption of the mentioned groups on the other floors. Additional energy meters for the building service systems, e.g. the cooling system and meters for the energy sources, e.g. the photovoltaic plant, enable a detailed analysis of the building's energy consumption and supply [2].

\section{Results}

In this chapter several results of the building's energy monitoring system are presented.

\subsection{Primary energy balance}

Fig. 4 displays the building's primary energy balance in the same way as already published in [2], but it is updated with the measured values of 2017 and 2018 . Additionally, there is now also an estimation for the balance of 2015 . The same observations as already discussed for the values for 2016 in [2], can be made for the monitoring estimates or results of the years 2015, 2017 and 2018: The building did not achieve its goal of providing enough energy for both consumption parts, usage and building. However, the energy supply needed to operate the building is easily met. The majority of the planned savings potential could be realized compared to the consumption of a typical new office building, but there is still room for improvement.

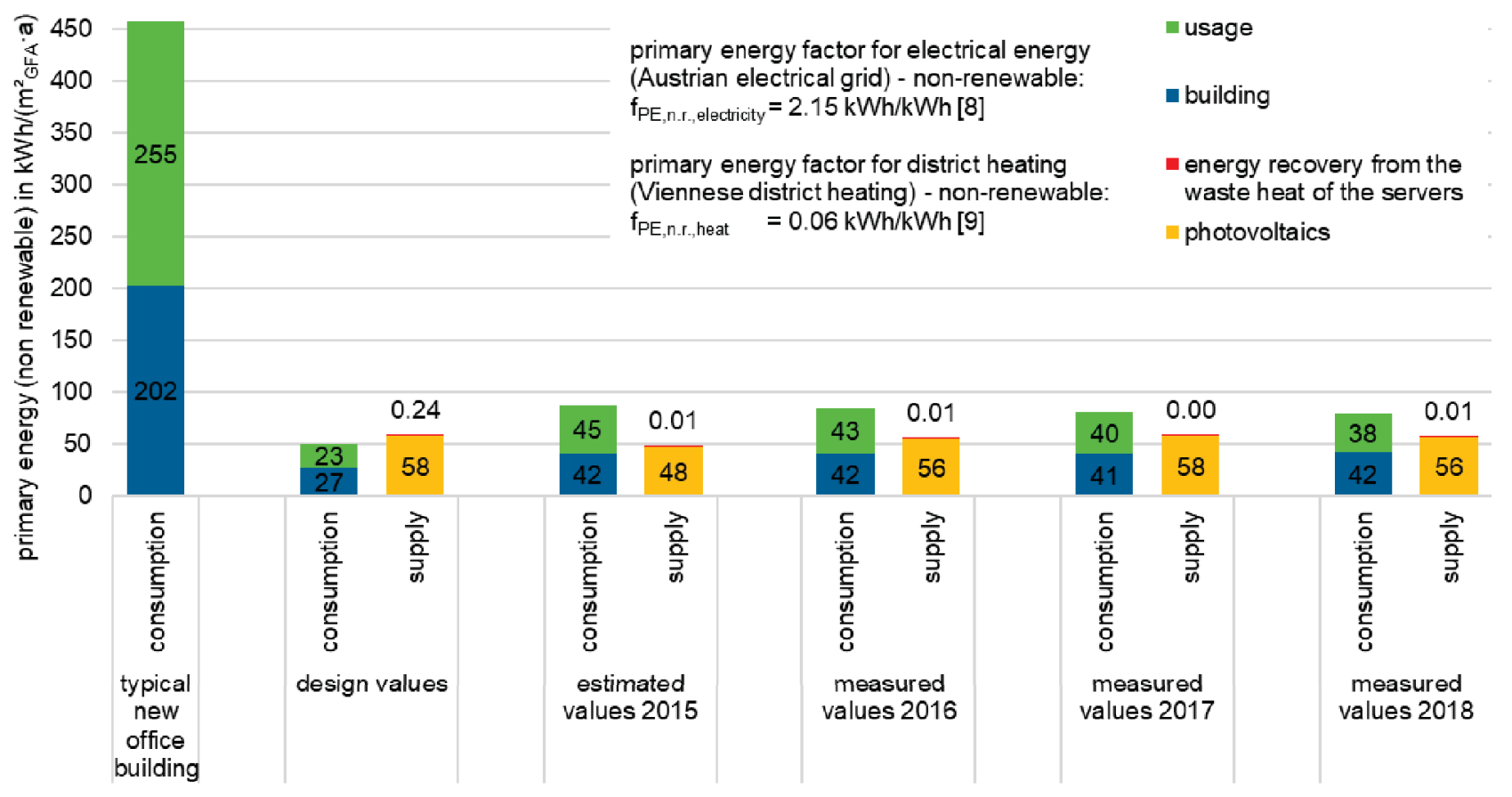

Fig. 4. Comparison of the planned values for supply and consumption with their respective measured values (primary energy). 


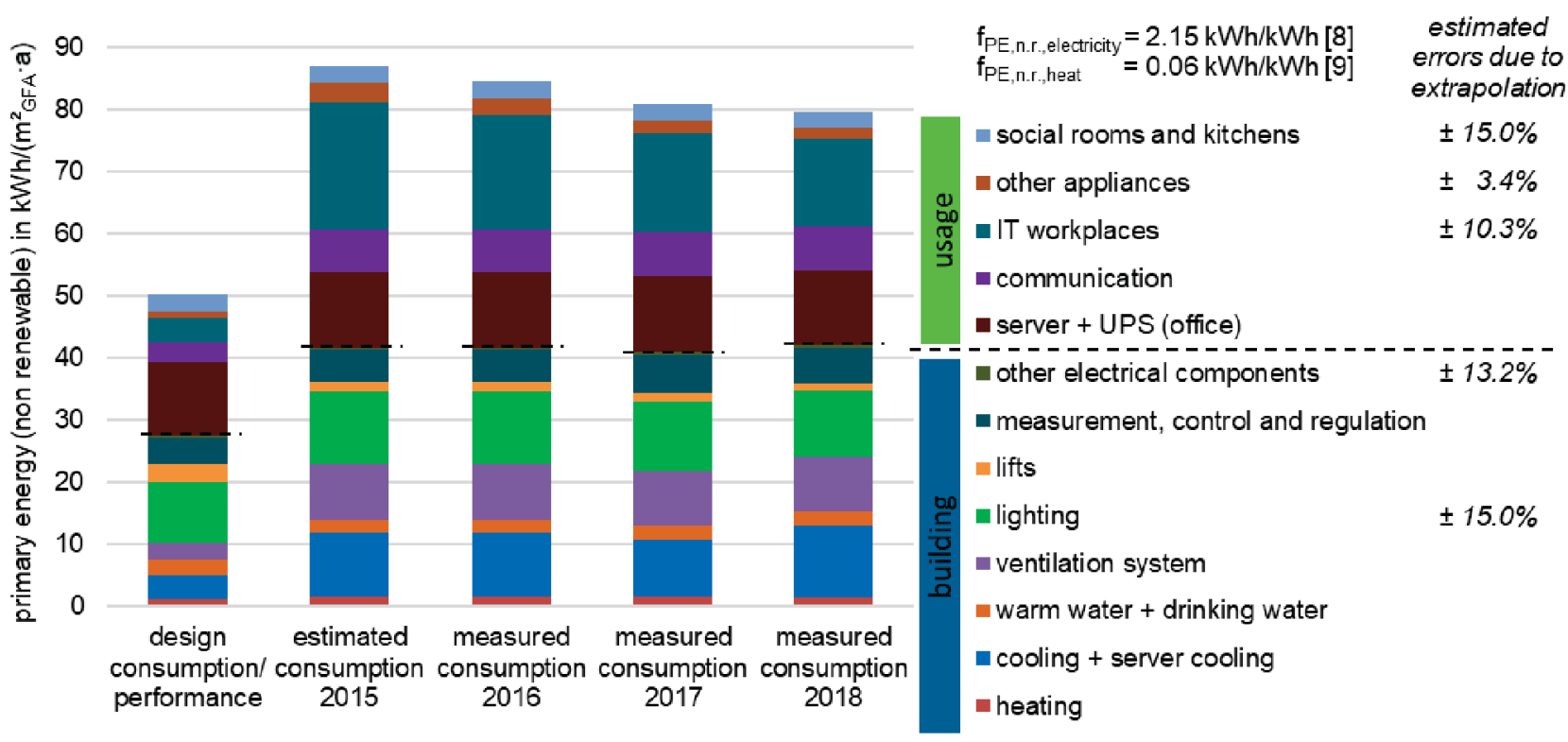

Fig. 5. Detailed comparison of the planned and measured consumptions (primary energy)

Note that the relatively low value of energy supplied by the photovoltaic plant during 2015 is due to the fact that parts of the photovoltaic system were not fully operational during the first months of 2015.

In Fig. 5 one can see the detailed comparison of the design consumption and the consumption measured during 2015-2018. Many of the reasons for the deviation of the measured consumption values from the corresponding design values were already discussed in [2]. However, there are two consumption categories, which need to be addressed again: The category "cooling + server cooling" and the category "IT workplaces".

In the category "cooling + server cooling" the main consumer is the building's chiller. The chiller did not operate with full efficiency during 2016 and it was expected that this issue would be fixed before the cooling period of 2017 [2]. The involved companies indeed adjusted the chiller's operational algorithm but shortly after that problems occurred which led to repeated automatic shutdowns of the chiller. It is suspected that the reason for these shutdowns was the pipe routing from the hybrid cooling towers to the chiller. Due to the fact that the building is a refurbishment, the pipe routing is more complex than in a new construction and thus air bubbles could potentially accumulate within the pipes. These air bubbles seem only to form when the chiller is operated with full efficiency. As a countermeasure the chiller's operation had to be adjusted and therefore it again operates less efficiently.

The category "IT workplaces" shows the combined energy consumption of the computer screens, office computers, laptops and workstations located in the building's office area. Comparing this category's consumption value of $2016,18.27 \mathrm{kWh} /\left(\mathrm{m}^{2}{ }_{\mathrm{GFA}} \cdot \mathrm{a}\right)$, with the value of $2018, \quad 14.13 \mathrm{kWh} /\left(\mathrm{m}_{\mathrm{GFA}}^{2} \cdot \mathrm{a}\right)$, clearly indicates that workstations were taken offline in the office area. Nevertheless, $14.13 \mathrm{kWh} /\left(\mathrm{m}_{\mathrm{GFA}}^{2} \mathrm{a}\right)$ is still significantly higher than the design value, which is $3.90 \mathrm{kWh} /\left(\mathrm{m}^{2}{ }_{\mathrm{GFA}} \cdot \mathrm{a}\right)$. There are several explanations for the difference between the design value and the measured consumption of 2018:

- On average there were still three workstations left on each of the eight office floors at the end of 2017.

- In the design value it was assumed that each workplace has only one energy efficient 24 " computer screen, in reality many of the workplaces are equipped with two, some even with more.

- The timespan during which the office equipment is used might have been underestimated in the design value. The building's occupants seem to work longer hours than expected.

- For the calculation of the design value it was assumed that each computer and its computer screen are switched off during the night. Some inspections of the building during the night showed that there were always a few workplaces for which this was not the case.

\subsection{Energy consumption of office floors}

The building's energy meters, which measure the total electricity consumption of each office floor, were operational since the beginning of the monitoring- and optimization project. Even though in the start there were issues with their parametrization, it was possible to evaluate their values for most months of 2015 .

Fig. 6 shows the mean daily electricity consumption of each floor in a monthly resolution and contrasts it with the value that each floor should have had according to the building's design. It can be seen that floor $\mathrm{H}$ is the floor closest to the design value over the whole monitoring period. The institute working on this floor already implemented the (Plus-)Plus-Energy Office High-Rise Building's usage concept right after the resettlement and uses almost only laptops and very energy-efficient desktop computers in the office area. The energy consumption profile of this floor during 2017 and 2018 proves that the said usage concept can successfully be implemented in an office building. 


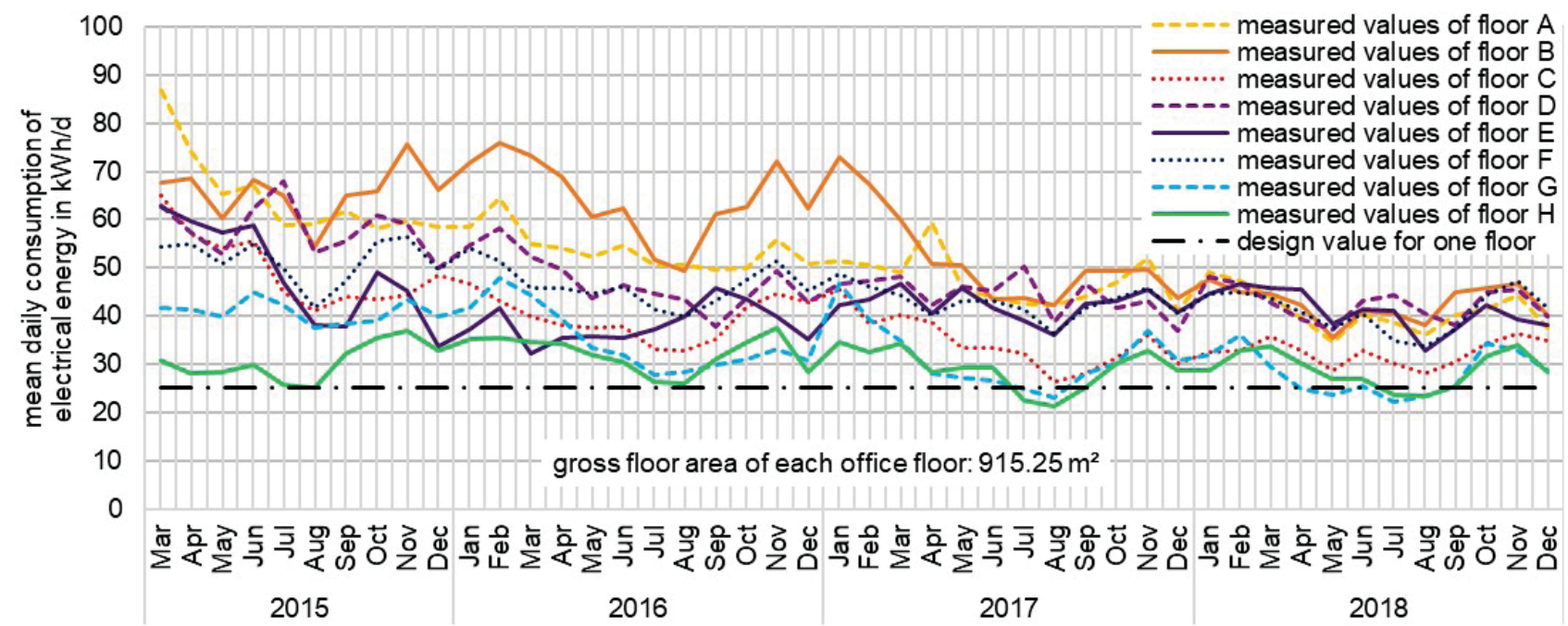

Fig. 6. Comparison of the measured average daily consumption of electrical energy of the Plus-Energy-Office High-Rise Building's eight office floors and the design consumption.

One can see the impact of the resettlement of the scientific IT in the energy consumption curves of the other floors depicted in Fig. 6. Especially the curve of floor B shows the magnitude of the energy consumption that can be accounted to the old workstations which were taken offline: The electricity consumption drops from a daily average of approx. $65 \mathrm{kWh} / \mathrm{d}$ in $2015 / 2016$ to a daily average of approx. $43 \mathrm{kWh} / \mathrm{d}$ in 2018 .

In 2018 two consumption pattern groups can be identified: One group around a mean of $40 \mathrm{kWh} / \mathrm{d}$ (floors A, B, D, E and F) and one around a mean of $30 \mathrm{kWh} / \mathrm{d}$ (floors $\mathrm{C}, \mathrm{G}$ and $\mathrm{H}$ ). This result is not surprising, because at the end of 2017 there was only one old workstation left on each of the floors $\mathrm{C}, \mathrm{G}$ and $\mathrm{H}$ while on all other floors there were four or more left.

\subsection{Energy consumption of the server room}

For Fig. 7 all consumption curves are aggregated and shown as the sum of all measured values of all floors. This combined curve shows a slow decrease from approx. $400 \mathrm{kWh} / \mathrm{d}$ in 2015 to approx. $300 \mathrm{kWh} / \mathrm{d}$ in 2018.

In the same period the energy consumption in the server room rose from approx. $350 \mathrm{kWh} / \mathrm{d}$ to approx. $550 \mathrm{kWh} / \mathrm{d}$. Note that the curve of the server room shows both the scientific and non-scientific part of the server room. As already depicted in Fig. 5, the energy consumption of the non-scientific part of the server room, namely the office part, which the file servers, web servers and database servers are attributed to, did not increase. Thus, the increase can be attributed to the new hardware, which took over the energy-intensive processes previously conducted on workstations directly in the offices. As already explained in the introduction and visualized in [2], the electricity consumption of the scientific part of the server room, is not included in the primary energy balance shown in Fig. 4 and 5 .

\section{Discussion}

Even though the energy consumption of the scientific part of the server room is not part of the building's primary energy balance, it should not be ignored. Especially now that the energy monitoring showed that the energy reduction in the office area caused an approx. twice as large energy increase in the server room.

This result should not be interpreted as an argument for keeping the old workstations in the office area. Only by getting rid of the thermal loads, which were caused by the old workstations, it became possible to achieve a comfortable indoor climate without an additional cooling

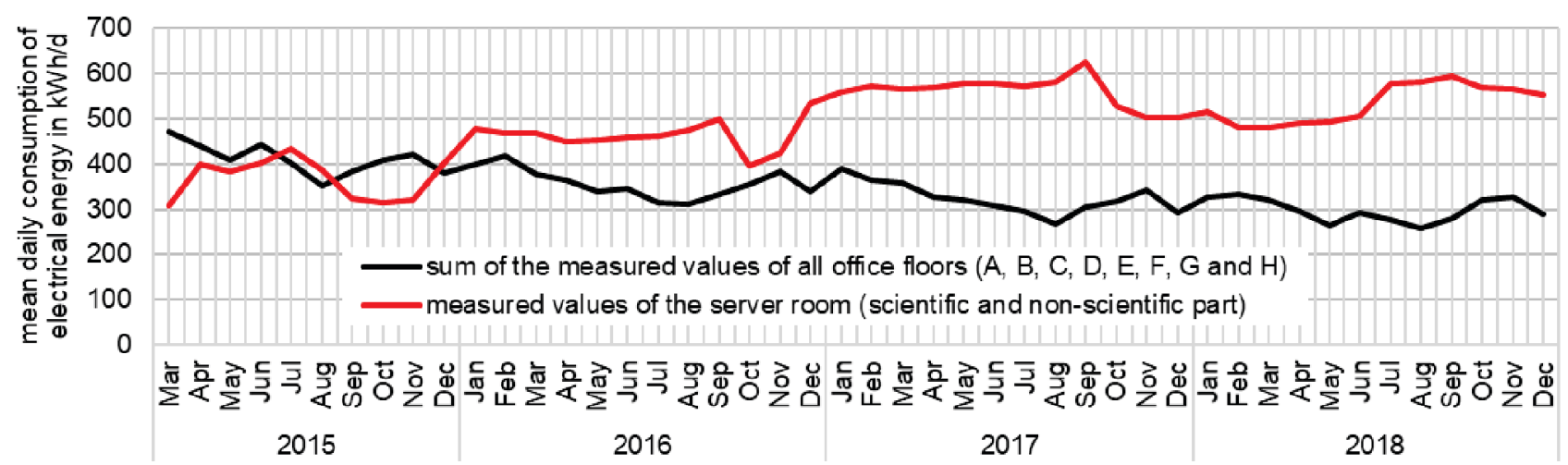

Fig. 7. Comparison of the measured average daily consumption of electrical energy of all of the Plus-Energy-Office High-Rise Building's office floors and the measured average daily consumption of its server room. 
system besides the underfloor cooling and the night ventilation system.

There are two main reasons why the scientific processes cause a higher energy consumption in the server room than in the office area:

- Many of the rack workstations were not suspended to hibernation mode when they were not needed. Instead they were left in idle mode. Even though it is possible to switch them to hibernation mode and wake them up via LAN, this mode was generally avoided due to user concerns. One of the concerns was that if the wake-up sequence did not perform as planned, the machine had to be restarted manually directly in the server room. As the access to the server room was restricted for security reasons, users tried to avoid this situation.

- The second reason seemed to be that many of the rack workstation's administrators did not switch their BIOS settings to the energy-efficient mode. By default, the rack workstations are set to standard mode. This needs to be evaluated further.

Even though the Linux servers and the servers for virtual machines are never suspended, they seem to be much less energy consuming than the rack workstations. Especially in the case of the idle state, it becomes obvious why using such servers, which can fulfill the computational needs of several users, is the more energy efficient solution. A servers' consumption while in idle state was approx. $230 \mathrm{~W}$, which is approx. three times the value of one rack workstation. As soon as one server is used by more than three users, it is more efficient in the idle state than three rack workstations in idle state.

The idle state is an important energy-efficiency indicator for servers, especially when considering that their utilization rate might be less than $10 \%$ [10].

\section{Conclusion}

The discussed relocation process resulted in a significant reduction of electricity consumption in the office floors and thus also in a significant reduction of the cooling load. Three of the building's eight office floors almost reached the ambitious design value.

When implementing the presented remote IT solutions in order to relocate energy-demanding processes from the office area to the server room, one should certainly develop a strategy how to deal with the energy consumption at times of low load. Otherwise one could have to deal with an overall increased electricity consumption.

For rack workstations there should be a procedure which ensures that the workstations are suspended to hibernation if they are not needed and there should be a practical solution to restart them manually if the WakeOnLan signal fails.

Generally, but especially in case of the rack workstations, there should be a procedure to ensure that the BIOS of the rack workstations and servers is set to an energy-efficient mode. Supervision by an independent party, e.g. a consultant for energy efficiency, should be part of this procedure.
Servers, which host virtual machines, seem to be the most reasonable solution in terms of energy efficiency and practicability. These servers promise better energy efficiency due to higher utilization rates as also pointed out by Uddin et al. [10]. Their virtualization technology is a key technology towards reducing energy usage [11], which is supported by the findings of this study.

The authors acknowledge the BMVIT (Federal Ministry of Transport, Innovation and Technology), Kommunalkredit Public Consulting GmbH and MA20 (Vienna's municipal department for "Energy Planning") for funding this project. The authors also acknowledge all projects partners, the TU Wien, the consortium of the Architects Hiesmayr-GallisterKratochwil as well as the Bundesimmobiliengesellschaft as the building owner and operator.

\section{References}

1. H. Schöberl, R. Hofer, M. Leeb, T. Bednar, Österreichs größtes Plus-Energie-Bürogebäude am Standort Getreidemarkt der TU Wien, Berichte aus Energie- und Umweltforschung, 47 (2014)

2. A. David, M. Leeb, T. Bednar, Comparison of the planned and the real energy consumption of the world's first (Plus-)Plus-Energy Office High-Rise Building, Energy Procedia, 132 (2017)

3. O. Hernandez, Elithis Tower in Dijon, France, REHVA JOURNAL, 48 (2016)

4. J. Stene, M.J. Alonso, Ø. Rønneseth, L. Georges, State-of-the-Art Analysis of Nearly Zero Energy Buildings, Country report IEA HPT Annex 49 Task 1 - NORWAY (2018)

5. Bundesministerium für Verkehr, Innovation und Technologie, University Plus-Energy Office HighRise Building, energy innovation austria, 5 (2016)

6. TU Univercity, Plus-Energy Office High-Rise Building, homepage accessed $12^{\text {th }}$ January 2020: https://www.univercity.at/plusenergyhighrise

7. M. Ziegler, A. David, T. Bednar, How Energy Efficiency Measures Influence and Simplify the HVAC Design at Austria's biggest Plus-PlusEnergy Office Building, CLIMA 2016 - proceedings of the 12th REHVA World Congress, 6 (2016)

8. Österreichisches Institut für Bautechnik, Energieeinsparung und Wärmeschutz, $O I B$ Richtlinie 6, (2011)

9. MA37, Konversionsfaktoren Wien Energie Fernwärme, Techniknovelle 2012, (2013)

10. M. Uddin, A.A. Rahman, Server Consolidation: An Approach to Make Data Centers Energy Efficient \& Green, IJSER, 1 (2016)

11. V. Motochi, S. Barasa, P. Owoche, F. Wabwoba, The Role of Virtualization towards Green Computing and Environmental Sustainability, IJARCET, 6 (2017) 